\title{
Isabel de Labayen: impresora y editora en la Pamplona del siglo XVII
}

\author{
Javier Ruiz Astiz*
}

Artículo recibido:

1 de marzo de 2021

Artículo aceptado:

27 de abril de 2021

Artículo de revisión

\section{Resumen}

Se estudia la figura de Isabel de Labayen, quien no fue solamente hija, mujer y madre de reputados impresores en la Navarra del siglo XVII, sino que incluso firmó algunas obras publicadas en su taller. Esclarecer esta actividad como impresora y editora será el propósito fundamental de este trabajo. Esto se consigue gracias a la información que nos ofrecen los pies de imprenta y los paratextos legales de ciertas ediciones, pero principalmente a través de los testimonios documentales conservados en archivos. Se pretende así reconstruir de la forma más fehaciente posible el papel que desempeñó esta mujer en el entramado editorial pamplonés de su época.

* Universidade da Coruña, Facultade de Humanidades e Documentación, España j.ruiz.astiz@udc.es

INVESTIGACIÓN BIBLIOTECOLÓGICA, vol.35, núm. 88, julio/septiembre, 2021, México, ISSN: 2448-8321 pp. 101-125 
Palabras clave: Isabel de Labayen; Impresora; Historia del Libro; Siglo XVII

Isabel de Labayen: printer and editor in $17^{\text {th }}$ century Pamplona

Javier Ruiz Astiz

\begin{abstract}
The figure of Isabel de Labayen is studied, a woman who was not only the daughter, wife and mother of renowned printers in Navarre in the seventeenth century, but who even signed some works published in her workshop. Clarifying this activity as a printer and editor will be the fundamental purpose of this work. This is achieved thanks to the information provided by the imprints and the legal paratexts of certain editions, but mainly through the documentary testimonies kept in archives. The aim is thus to reconstruct in the most reliable way possible the role that this woman played in the Pamplona publishing network of her time.
\end{abstract}

Keywords: Isabel de Labayen; Printer; Book History; XVII ${ }^{\text {th }}$ Century

\title{
INTRODUCCIÓN
}

$\mathrm{E}^{\mathrm{n}}$ n el Diccionario de mujeres impresoras, libreras y editoras, lo poco que nos dice su autora de Isabel de Labayen es que su figura "y su relación de parentesco con la familia Labayen, evidenciada por el apellido común, ha generado numerosas dudas" (Establés Susán, 2018: 327). A eso viene el presente estudio, a despejar las posibles incógnitas que aún pueden existir sobre dicha mujer, aunque esta investigación deba engarzarse en toda una serie de trabajos de corte histórico y bibliotecológico que han contribuido a esclarecernos el papel que realmente ostentó la mujer a lo largo del Antiguo Régimen. Por todos es conocido que su papel solía verse reducido al ámbito privado, por lo que en el entramado laboral y económico de la época su protagonismo era más bien testimonial o residual. No obstante, la realidad dista mucho de ser tan tajante, ya que los testimonios documentales conservados en numerosos archivos 
nos dejan entrever a mujeres que también ostentaron un papel protagonista en ciertas circunstancias. Hasta la fecha, varios han sido los trabajos que han conseguido demostrar que ciertas mujeres tuvieron una destacada relevancia en el ámbito editorial frente al ostentado por otras en diversas actividades financieras. Cabe resaltar aquí a Fernández Vega (2004), Pedraza Gracia (2009), Garone y Corbeto (2011) o Ulla Lorenzo (2018), entre otros y otras, para el ámbito hispano. Pese a estos avances, somos conscientes de que nuestro conocimiento sobre la actividad real de las mujeres en la imprenta durante los siglos modernos es limitado. Por tanto, y dadas las circunstancias, cabe afirmar que aún faltan más aportaciones que permitan comprender el grado de participación real de las mujeres en la historia del libro y de la imprenta.

Siendo así, lo cierto es que este trabajo viene a sumarse a sus predecesores para redescubrir a aquellas mujeres que se hallan invisibilizadas tras los nombres de los hombres de sus familias: padres, maridos e hijos. Debido a esto, para indagar sobre el papel que desempeñó al frente de cualquier taller una mujer, no nos podemos remitir tan sólo a los impresos conservados porque rara vez nos dan información más allá de los pies de imprenta y colofones. En consecuencia, para la consecución del presente artículo son varios los recursos archivísticos que tenemos a nuestro alcance para sumergirnos como recomendaba Infantes de Miguel (2012: 137-138) - en la historia interna tanto de los impresos editados como de los talleres de imprenta (personal, materiales, infraestructura y organización) a lo largo del Antiguo Régimen.

El reflejo de aquellas realidades encubiertas se aprecia en varias tipologías documentales, aunque en esta investigación se ha dado preferencia a las dos fuentes de archivo que se muestran más ricas en cuanto a la información que aportan: la documentación procesal y las escrituras notariales. Ambas nos van a permitir tratar diversos asuntos:

a) Confrontar la Historia del Libro actual con la que se practicaba hasta hace poco.

b) Señalar las fuentes documentales que podemos consultar para rescatar del olvido a ciertas mujeres relacionadas con el libro antiguo en la Navarra del siglo XVII.

c) Profundizar en la metodología empleada y su puesta en práctica como ejercicio pedagógico e instructivo con una perspectiva de género.

d) Ahondar en el papel real que ostentaron ciertas mujeres -en especial Isabel de Labayen- en los talleres de imprenta para calibrar su grado de implicación con lo que se editaba.

e) Acercar a los lectores un tema sobre el que aún hay mucho por descubrir, pese a que ya existen algunos estudios que han arrojado interesantes datos. 
No hay duda alguna de que más allá de los repertorios bibliográficos, es gracias a los archivos históricos que conseguimos rescatar fieles testimonios de los avatares sufridos por muchas mujeres en los talleres de cualquier ciudad durante los siglos modernos (Ulla Lorenzo, 2018: 336). Sólo así obtendremos una imagen lo más fidedigna posible del papel de algunas de ellas. Por tanto, en este trabajo nos vamos a referir al empleo de documentos de archivo para conocer más a fondo la figura de Isabel de Labayen.

Su papel como impresora y editora, además de propietaria-regente de un taller, ha sido posible a través del examen de diversos documentos de archivo y de impresos de la época. Dentro de los primeros se han analizado algunos procesos judiciales entablados ante los Tribunales Reales de Navarra, así como las escrituras notariales que se han localizado sobre Isabel de Labayen conservadas en el Archivo General de Navarra. De su estudio se han obtenido interesantes datos sobre su labor en el entramado editorial navarro de su época para, entre otras cosas, denunciar el olvido y la ausencia sistemática de las mujeres en la historia del libro y de la imprenta.

\section{LA PRESENCIA DE LA MUJER EN EL ENTRAMADO EDITORIAL}

Hace unos años Corbeto López (2009: 22) afirmaba que "los antiguos bibliógrafos omitieron o infravaloraron la participación de las mujeres en la tipografía antigua". Siguiendo su estela podríamos señalar que la figura femenina ha pasado por dos procesos de ocultación a lo largo de la historia de la imprenta. Por un lado, tendríamos que referirnos a la propia realidad de su época, ya que durante el Antiguo Régimen el papel de las mujeres se vio reducido habitualmente al de ser hija, esposa, viuda y madre de un hombre. A su vez, por otra parte, deberíamos ser conscientes del poco interés que ha despertado entre los estudiosos este tema hasta hace dos décadas, al menos en lo que a España hace referencia.

Partiendo de esta base, cabe resaltar que Delgado Casado (1996) recoge cerca de 230 menciones a mujeres con sus nombres completos o como viudas (sin mención alguna de su verdadero nombre) en las imprentas hispanas entre los siglos XV y XVII de un total de 939 referencias. Es decir, en $24.5 \%$ de las entradas que señala aparecen menciones a féminas. Esta es, sin duda, una cifra nada desdeñable. Por su parte, Establés Susán (2018) recopila un total de 415 mujeres desde el siglo XV hasta el XVIII. Es decir, mujeres aparecen, pero hay que ir más allá de recoger menciones en pies de imprenta y colofones, pues de ese modo no somos conocedores del papel real que tuvieron muchas de ellas. 
De forma genérica sabemos que a lo largo de la Edad Moderna aparecen mujeres asumiendo el control de algunos talleres de imprenta, como los casos de Mariana de Montoya en Baeza (Sánchez Cobos, 2004) o Juana Martínez de Angulo en Alcalá de Henares (Vázquez Madruga, 2010). Por lo general, estas situaciones solían ser fruto del fallecimiento de sus padres o de sus esposos, lo que nos evidencia que habitualmente adquirían un rango de mayor relevancia gracias al traspaso de la propiedad de un negocio. Esta realidad nos permite entender que la presencia de las mujeres en el entramado editorial no solía ser voluntaria, sino que por lo general se convertían en las herederas de un taller con todos los instrumentos y materiales que habían sido reunidos por los hombres de su familia.

Pese a esto, lo importante es que hubo casos en los que ciertas mujeres no se limitaron a terminar ciertos encargos editoriales y delegar su actuación en sus oficiales y aprendices. Así, se aprecia que se mantuvieron al frente de sus negocios durante un tiempo prolongado -incluso varias décadas-, actuando como verdaderas gestoras y editoras. No obstante, aun siendo conscientes de que su protagonismo fue mayor del que se intuye a simple vista gracias a las menciones de responsabilidad advertidas en portadas y colofones (Garone y Corbeto, 2011: 105), lo cierto es que para redescubrir su grado de implicación en numerosos talleres debemos recopilar testimonios documentales que nos hablen de su vida cotidiana, privada y profesional.

Aun siendo conscientes de que se trata de un gremio sumamente endógeno y que lo frecuente es que la mujer actúe como mera transmisora del negocio de imprenta en favor de un varón, es cierto que gracias a las fuentes archivísticas se constata que en las prensas hispanas también se registraron casos de mujeres que participaron de forma activa en numerosos talleres. Son muchos los testimonios que nos quedan aún por descubrir para mostrar su verdadero papel, pero puede que a lo largo del siglo XVII su presencia -tal y como expuso Pedraza Gracia (2009: 57) - aumentase notablemente, algo lógico por el mayor número de imprentas que trabajaron en dicha centuria distribuidas por la actual geografía española.

Siendo esto cierto, podemos afirmar que la intervención de las mujeres en la imprenta pamplonesa ha de calificarse como trascendental si tenemos en cuenta que las relaciones de parentesco fundamentaron muchas de las transmisiones de los negocios editoriales. Sin embargo, su visibilidad se ve reducida en Navarra, por lo general, a los pies de imprenta y los colofones. En ellos advertimos a varias viudas, las cuales nunca aparecen nombradas, puesto que se identifican impresos publicados por la viuda de Matías Mares, Carlos de Labayen y Martín Gregorio de Zabala. Todas ellas aparecen, pero sus verdaderos nombres no se citan: Isabel Delgado, Felipa Rodríguez y María de Álava, respectivamente. 
Frente a esta triste realidad, debemos resaltar la figura de nuestra protagonista. Así, Isabel de Labayen se diferenció de sus colegas -como se verá en las próximas páginas- porque sí dispuso su nombre en varios impresos. Este hecho, unido a los testimonios documentales localizados en el Archivo General de Navarra, nos permite indicar que esta mujer fue un caso extraordinario en la escena local, ya que gestionó y controló el taller de imprenta radicado en Pamplona durante varios años, aunque principalmente sería entre 1669 y 1670 cuando tuvo un papel más activo.

\section{UNA HEREDERA Y PROPIETARIA DEFENDIENDO SU NEGOCIO}

Como hemos señalado con anterioridad, las mujeres a lo largo del Antiguo Régimen son reconocibles como hijas, esposas, viudas y madres de algún hombre. En este caso no iba a ser menos. Sabemos que Isabel de Labayen fue la única hija del matrimonio entre Martín de Labayen (impresor) y Ana Marrón. Siendo heredera del negocio de su padre se casó en 1643 con su primer marido, Diego de Zabala, pero en 1655 enviudó y contrajo segundas nupcias ese mismo año con otro impresor: Gaspar Martínez. Pero este no fue el único hombre importante de su trayectoria vital, ya que uno de los hijos que tuvo en su primer matrimonio -Martín Gregorio de Zabala- fue quien se hizo cargo del negocio, además de darle algunos problemas que veremos más adelante.

Se ha indicado que el verdadero protagonismo de Isabel de Labayen se produjo entre 1669 y 1670, pero la primera vez que la encontramos mencionada en un documento de archivo mostrando su papel como heredera y propietaria data de junio de 1643. Tanto es así que se aprecia que siempre fue una mujer que luchó por lo suyo para conseguir la mera supervivencia de su legado familiar y de su negocio. En dicho año aparece junto a su primer esposo -Diego de Zabala- en un poder notarial dado contra Domingo Vélez de Bergara. En él le reclamaban a este último "como atenedor de los bienes de Felipa Rodríguez, su mujer y ya difunta sobre ciertas cantidades de dinero" (Archivo General de Navarra. Tribunales Reales, Procesos, núm. 31023, fol. 7r).

Vélez de Bergara se había casado en segundas nupcias con Felipa Rodríguez, quien primero se unió en matrimonio con Carlos de Labayen, tío de Isabel. Dada esta situación el padre de Isabel -Martín de Labayen- salió en su defensa en el pleito al argumentar que la difunta debía 40 ducados por una escritura en la que había dejado Carlos de Labayen en 1632 dicha cantidad para su sobrina. El propio Martín señalaba que: 
se concertó con Felipha Rodríguez, viuda de Carlos de Labayen, así bien impresor de libros ya difunto, en que por los alimentos que el dicho Carlos de Labayen dexó en su último testamento le diese a Isabel de Labayen, sobrina del dicho Carlos de Labayen e hija del dicho otorgante y la dicha Felipha Rodríguez, por escusarse de llevar y tener en su casa criando y alimentando a la dicha Isabel de Labayen se convinieron en que la dicha Felipha Rodríguez le hubiese de dar al dicho Martín de Labayen por los dichos alimentos que el dicho Carlos de Labayen le dexó en su dicho testamento a la dicha Isabel de Labayen la suma de cuarenta ducados pagados aquellos en ocho años. (Archivo General de Navarra. Tribunales Reales, Procesos, núm. 31023, fol. 8r)

Tenemos constancia de que Felipa Rodríguez había fallecido en 1637 y que en su testamento excluyó a su segundo marido de la herencia, ordenándole la venta de la imprenta para pagar los sufragios que había encargado por su alma. Ella, pese a reconocer "lo mucho que ha cuidado de mí y en trabajar en el oficio de la imprenta" y los cuidados que le ha dispensado en la enfermedad, sólo concedió a su marido el "cajón" de la plaza del Consejo Real y los primeros 100 ducados de la venta de la imprenta, que estimaba que produciría quinientos en total, aunque se lamentaba de no "tener mucho más para poderle dejar" (Archivo General de Navarra. Tribunales Reales, Procesos, núm. 31023, fol. 21r).

Sea como fuere, Domingo Vélez retrasó la venta del taller y con ella el pago de las mandas testamentarias. Esta premeditada dilación en el pago de dichas mandas afectaba a los herederos, como era el caso de Isabel de Labayen, sobrina de Felipa Rodríguez, a la que le correspondían cien ducados. Para cobrarlos tuvo que presentar una demanda judicial en 1643, la cual se resolvió a su favor al año siguiente.

Con este testimonio documental se pone de manifiesto que Isabel era consciente de que el negocio de imprenta era suyo por su herencia paterna, lo que nos ayuda a entender el modo en que defendió su posesión. Como vamos a ver, a lo largo de la Edad Moderna todos los agentes implicados en el negocio editorial comparecieron ante los jueces fruto de las demandas interpuestas por fraudes, incumplimientos de acuerdos, etc. Así, resulta habitual encontrarse para la Navarra áurea tanto a impresores como libreros (Ruiz Astiz, 2015: 332-339) defendiendo sus derechos ante las intromisiones llevadas a cabo por quienes rivalizaban con ellos en la producción y comercialización del libro antiguo. Esto nos permite apreciar a todos aquellos personajes como entes fiscalizadores en todo lo que estaba relacionado con la edición y venta de impresos, pero también nos introduce en la esfera privada de muchos de sus protagonistas.

No hay duda de que esto se complica cuando queremos reconstruir los avatares vividos por muchas mujeres y más con aquellas que estaban involucradas 
en el mundo de la imprenta. De este modo, en la línea de lo que señala Garone (2008: 453), encontrar información sobre mujeres impresoras más allá de los pies de imprenta o de los colofones no es nada sencillo, de ahí que sea escasa la información que se ha sistematizado hasta el momento sobre su verdadero protagonismo.

Esto mismo nos sucede con Isabel de Labayen, ya que, como veremos en el próximo apartado, son pocos los testimonios bibliográficos con los que contamos, de ahí que éstos no nos permitan calibrar con certeza su actividad dentro del taller de imprenta. Sin embargo, será junto a los recursos archivísticos como conseguimos esbozar su papel como dueña, regente, impresora y editora. Y estas funciones las asumió de forma temprana, ya que como hemos visto, Isabel fue una firme defensora de sus derechos como propietaria y heredera del legado de su padre, incluso de su tío Carlos.

Hemos señalado que, tras enviudar de Diego de Zabala, se casó con Gaspar Martínez, otro impresor que venía de Zaragoza. Fue con él cuando vivió una situación marital adversa que le afectó tanto a nivel personal como familiar, ya que el taller de imprenta sufrió el abandono de su impresor jefe. Dada esta situación, Isabel no dudó en ponerle una querella por malos tratos y otros asuntos a mediados de 1662. Así, el 17 de julio era su procurador, Joan Fernández de Mendibil, quien se refería a Isabel como "impresora y vecina de esta ciudad", la cual "dice que reconociendo la mala vida que Gaspar Martínez, su marido, le da castigos tan eccesivos que en ella hace sin causa ni razón más que llevado de sus disinios particulares jabtandose de que la ha de matar". A esto se añadía que Martínez le robaba material del taller: "rapartando de casa los bienes y pagándolos al reino de Aragón como con efecto lo ha hecho llevando a la ciudad de Zaragoza más de catorce arrobas de letras".

Debido a todo esto, Fernández de Mendibil señalaba que "se ha resuelto mi parte a poner demanda de divorcio ante el vicario general y ya la ha puesto viendo que por ningún medio que mi parte ha puesto para que se apartara el dicho su marido de los divertimentos que tiene y castigos que ha hecho en ella y en sus hijos de primer matrimonio" (Archivo General de Navarra. Protocolos notariales, Caja 19257, Legajo 1, núm. 190, fol. 1r).

Dos días después se interpuso una demanda ante los Tribunales Reales de Navarra ${ }^{1}$ sobre apropiación indebida de bienes y haber ocultado con dolo y malicia en Zaragoza diversos materiales de imprenta pertenecientes a la demandante. Por tanto, nos encontramos en 1662 a Isabel de Labayen siendo reconocida como dueña del taller y de todos sus materiales y ella 
aparece luchando por su legado familiar y por el mantenimiento del negocio en el que ya están trabajando como aprendices de impresores sus hijos Martín Gregorio y Francisco.

Aquella situación provocó que Isabel se pusiese al frente del taller, y ante la ausencia de su segundo esposo, aparecerá defendiendo el negocio sola, lo que se evidencia del poder notarial que suscribió el 19 de enero de 1667. En él nombraba a Diego Felipe Pérez como su procurador "para un pleito que la susodicha pretende llevar en los tribunales reales de este reyno contra el Padre Josep Moret de la compañía de Jesús y Lorenço Coroneu, mercader de libros, residente en la misma ciudad, sobre el desembargo del repertorio de las leyes de este reyno y el valor de su impresión" (Archivo General de Navarra. Protocolos notariales, Caja 19349, Legajo 1, núm. 4, fol. 1r).

En este caso vemos que Isabel solicitaba el desembargo de la obra Repertorio de todas las leyes promulgadas en el Reyno de Navarra que en 1666 habían impreso sus hijos Martín Gregorio y Francisco. Aquella situación se produjo porque Moret reclamaba unas deudas a Gaspar Martínez (Ruiz Astiz, 2020: 61), ausente en Zaragoza, por lo que pidió el embargo de los materiales del taller. Entre ellos dicho repertorio, pero ¿por qué lo solicitaba?

El 31 de agosto de 1666 fue José Moret quien presentó un auto de embargo contra los bienes de Martínez. Entre aquellos se encontraba dicha obra, ya que como indicó Francisco de Zabala -hermano de Martín Gregorio-: "el dicho Gaspar Martínez ha trabajado algunos tomos de las leyes de este reino compuestos por Sebastián de Irurzun". Señalaba, a su vez, "que todos los tomos que así se han trabajado se han entregado al dicho Sebastián de Irurzun y a Lorenço Coroneu, ezepto diez pliegos que tiene escritos de mano el declarante para imprimirlos del sumario", lo que provocó que a la hora de proceder al embargo el escribano señalase que "cogí a mano real los dichos diez pliegos originales y pliego y medio compuestos del dicho sumario general hasta que por el Real Consejo otra cosa se provea" (Archivo General de Navarra. Protocolos notariales, Caja 19514, Legajo 2, núm. 1, fol. 3r).

Lo relevante de este hecho es que Isabel se muestra como la regente de su taller al encabezar las demandas judiciales para defender su negocio, algo que se repetirá en 1668 cuando haga frente a la intromisión de otros libreros locales, solicitando el embargo de ciertos impresos que se estaban comercializando sin su consentimiento. Así, vemos que testifica que "desde el año de sesenta y seis último pasado han hallado haberles faltado de la casa de la susodicha mil y quinientos artes de Antonio de Nebrija y otros mil y quinientos libros cuartos", los cuales "por diligencias que han hecho en todo este tiempo no se han podido descubrir hasta que el día catorce de este presente mes se supo encuadernaban Juan de Enciso y Joan Micón, libreros, grande cantidad de ellos". 
Es decir, algunos títulos habían desaparecido de su taller y había ciertos personajes que los estaban encuadernando en Pamplona para venderlos. Pero, ¿cuál era el problema? Muy simple, la posesión del privilegio de edición, lo que facultaba a Isabel de Labayen a su comercialización en exclusiva en Navarra "y no poderlos otra ninguna persona tener por gozar de privilegio de vuestro Real Consejo", ante lo que Isabel pedía que "por ser robo tan manifiesto y hacienda de menores suplica a vuestra majestad mande proveer de auto de embargo" (Archivo General de Navarra. Tribunales Reales, Procesos, núm. 165001, fol. 7r).

A lo largo del proceso judicial se advierte quién había sido el causante de esta situación, pues Juan de Enciso declaró que "con orden de Lorenzo Coroneu se le han entregado habrá como ocho días hasta doscientos artes y libros cuartos, ciento de unos y quinientos de otros". Algo idéntico a lo señalado por Joan Micón, quien afirmó que "se halla encuadernando cien libros artes de gramática de Antonio Nebrija y otros cien libros cuartos los cuales se los entregó para dicho efecto Lorenzo Coroneu" (Archivo General de Navarra. Tribunales Reales, Procesos, núm. 165001, fol. 7v).

Esto explica que, ante la ilegalidad que estaba cometiendo Coroneu junto a Enciso y Micón, Isabel alegase que su segundo esposo, Gaspar Martínez, tenía el privilegio para editar ciertas obras y así el secretario del Consejo Real de Navarra, José Martínez, señalaba el 20 de junio de 1668 que era cierto que a dicho impresor "se le concedió licencia y facultad para que por tiempo de dos años contados del sobredicho día que va expresado pudiera vender el arte de Antonio de Nebrija y libro cuarto, Doctrina Cristiana y Cartilla con prohibición que otras personas no los pudieran vender sin consentimiento del susodicho" (Archivo General de Navarra. Tribunales Reales, Procesos, núm. 165001, fol. 9v).

En definitiva, nos encontramos a Isabel de Labayen solicitando a través de su procurador, Joan Antonio de Salcedo, que "ninguna persona puede vender el arte de Antonio de Nebrija, la doctrina cristiana y cartilla sino mis partes con que se debe proveer el auto de embargo que tiene pedido mi parte para que los que se hallan en poder de la parte contraria estén de manifiesto y no se puedan vender contraviniendo a la dicha prohibición" (Archivo General de Navarra. Tribunales Reales, Procesos, núm. 165001, fol. 14r).

Apreciamos a una mujer luchando por su negocio de manera decidida, algo que la llevó incluso a enfrentarse a su hijo Martín Gregorio de Zabala. Así, en 1669 fue este último quien le denunció por la posesión del taller familiar, ya que alegaba que "siendo el suplicante dueño absoluto de la imprenta por muchos títulos respecto de haberse casado le priva su madre Isabel de Labayen de su tenencia y posesión, siendo así que no hay razón alguna para 
ello porque habiendo sido parte de la dicha imprenta de Martín de Labayen, su padre, después que contrajeron matrimonio los padres del suplicante le hizo donación de ella a tiempo que el dicho Martín Gregorio de Zabala tenía tres meses y en la dicha donación dice que lo que le mueve a hacerla es porque Diego de Zabala, padre del suplicante, murió a aveintestato, y por haberse vuelto a casar luego la dicha su madre Isabel de Labayen con Gaspar Martínez, criado suyo" reclamaba lo que consideraba que era su herencia porque su padrastro "se hubo de ausentar por la mala vida que le daba". Fruto de esa situación "vino a esta ciudad por enviarlo a llamar para su asistencia y gobierno de la dicha imprenta" (Archivo General de Navarra. Tribunales Reales, Procesos, núm. 76675, fol. 1ro).

A esto añadía que "dicha imprenta y de todo lo demás que les pertenecía a los hijos del primer matrimonio ha sustraído y llevado su padrastro, pues compró una vara de portero real en seiscientos escudos que él está ejercitando en la ciudad de Zaragoza". Junto a esto, era "voz común y fama pública todo lo referido respecto de haber estado preso el dicho su padrastro tres meses en vuestras cárceles reales por faltar de la dicha imprenta más de treinta arrobas de letras". Fruto de aquella situación se quejaba Martín Gregorio porque "empeñándolos para ello y obligándose a la dote de doscientos y cincuenta ducados y estando desamparada dicha imprenta y sin tener que trabajar cosa alguna pereciendo actualmente toda la casa ha restaurado la mala opinión que dejó el dicho su padrastro".

Para enmendar esto señalaba que había estado "buscando qué trabajar para el sustento de la dicha su madre, hermanos y demás familia haciendo composiciones y ajustes con el colegio de la Compañía de Jesús para evitar se sacasen las conclusiones y otras cosas que se llevaban a imprimir a Bayona de Francia, Logroño y otras partes". Era tal su desesperación que señalaba que no era justo que "por no tener la dicha imprenta el suplicante se lleven a otros sitios las impresiones en gran detrimento del gobierno político y comodidad de los naturales". Ni, además, "tampoco sería razón y molestia de esta república esté pendiente del dominio de la madre del suplicante la máquina de las impresiones de este vuestro reino y más cuando hay impresor en él a quien le ha sido dado derecho y títulos y prerrogativas" (Archivo General de Navarra. Tribunales Reales, Procesos, núm. 76675, fol. 1v).

Ante esto solicitaba al juez que "se le ha de conceder la propiedad de la dicha imprenta y pueda redundar en provecho del bien común", por lo que "suplica a vuestra majestad sea servido mandar ser la posesión, tenencia y administración de la dicha imprenta suya para que como tal dueño e impresor en vuestro reino pueda usar absolutamente de su profesión aunque sea con el gravamen de dar a la dicha su madre los alimentos que vuestro Consejo 
mandare" (Archivo General de Navarra. Tribunales Reales, Procesos, núm. 76675, fol. 2r).

Cabe preguntarse qué hizo Isabel de Labayen ante el ataque que le dirigió su hijo mayor. La respuesta a la demanda recibida a finales de 1669 la encontramos poco después -el 11 de enero de 1670-, pues nuestra protagonista aparece suscribiendo un poder donde señalaba que "trata llevar pleito en los tribunales reales defendiendo contra Martín Gregorio de Zabala, su hijo, sobre ciertos intereses que le pide". La citada indicaba que lo realizaba "en virtud de poder general que tiene la otorgante de Gaspar Martínez, su marido, que está ausente, por el cual le tiene con él da licencia para seguir cualesquiera pleitos que le fueren puestos y hacer escrituras y lo demás que le convenga" (Archivo General de Navarra. Tribunales Reales, Procesos, núm. 76675, fol. 4r).

Por todo ello nombraba a Joan de Araiz como su procurador ante los Tribunales Reales de Navarra. La contienda legal comenzaba entonces, de ahí que Martín de Ilarregui, procurador del demandante, señalase en favor de Martín Gregorio "que la dicha imprenta recibe mucho daño de que no trabaje en ella mi parte por el mal despacho que hay de que se quejan todos y toman motivo de llevar las impresiones a Logroño y Bayona". A esto añadía que "mi parte por no tener en que usar su oficio de impresor por retenerlos su madre se halla sin tener con que poder cumplir con la obligación que hizo de las impresiones ni tampoco tiene con que alimentarse", por lo que "suplica a vuestra majestad mande que la dicha Isabel de Labayen le entregue a mi parte la imprenta para que pueda cumplir con la obligación de su oficio de impresor" (Archivo General de Navarra. Tribunales Reales, Procesos, núm. 76675, fol. 16r).

Además, para su defensa Martín Gregorio presentó los nombramientos como impresor del reino y de la ciudad de Pamplona, los cuales se produjeron entre diciembre de 1668 y enero de 1669 para suplir la ausencia de su padrastro. De todos modos, pese a los argumentos esgrimidos por la parte demandante, encontramos a Joan de Araiz, procurador de Isabel, alegando que "mi parte es dueña propietaria de la imprenta y sus materiales y letras en virtud de la donación que su padre le hizo y demás cosas que en ella se contienen". Y estaba la susodicha "en quieta y pacífica posesión, y trata el dicho su hijo de inquietarla con este pleito" (Archivo General de Navarra. Tribunales Reales, Procesos, núm. 76675, fol. 27r).

Tras las alegaciones de ambas partes, finalmente la Corte navarra acordó "que Isabel de Labayen arriende la imprenta a Martín Gregorio Zabala y no conviniéndose en el precio la dicha Isabel de Labayen reciba en el uso de la imprenta y para trabajar lo que en ella se hubiere de imprimir al dicho Zabala 
pagándole el salario que mereciere cada día por su ocupación” (Archivo General de Navarra. Tribunales Reales, Procesos, núm. 76675, fol. 28r).

Pero parece que Isabel no quiso transigir con esta sentencia y así Martín de Ilarregui, procurador de Zabala, indicaba que "la dicha Isabel de Labayen no ha querido dar a mi parte en arrendación dicha imprenta, y solo quiere admitir a mi parte pagándole el salario como a un oficial, con el cual no puede mantenerse ni asistir a mi parte en la dicha imprenta respecto de que está casado" (Archivo General de Navarra. Tribunales Reales, Procesos, núm. 76675, fol. 29r).

Sin embargo, la decisión del juez fue ratificada en segunda instancia, por lo que "no conviniéndose en el precio la dicha Ysabel de Labayen reciba en el uso de la emprenta y para trabaxar lo que en ella se hubiere de imprimir al dicho Zabala pagándole el salario que mereciere cada día por su ocupación" (Archivo General de Navarra. Tribunales Reales, Procesos, núm. 76675, fol. 30r).

Esto último, como se verá en el próximo apartado, explicará que en 1669 y 1670 aparezcan varios impresos en cuyo pie de imprenta encontramos el nombre de Isabel de Labayen. Lo relevante es que aquel enfrentamiento directo con su hijo perduró más allá de 1670, ya que en 1671, con el regreso de su segundo esposo, nos encontramos con una denuncia ante los Tribunales Reales que formaron ambos contra Martín Gregorio. Sabemos que el padrastro habría vuelto para ese último año de Zaragoza, pues así lo indica en su alegato, a lo que añadirá una serie de quejas contra su hijastro: "y agora habiendo vuelto a esta ciudad a continuar con la imprenta que tiene en ella y vivir con su mujer e hijos y familia el dicho Martín Gregorio de Zabala en virtud de la dicha provisión de vuestro consejo trata de embarazarle el que no imprima las dichas cédulas y memoriales ajustados en grave perjuicio pretendiendo que él solo las ha de imprimir" (Archivo General de Navarra. Tribunales Reales, Procesos, núm. 76784, fol. 1r).

Asimismo, indicaba Martínez que "si se diese lugar a la pretensión contraria el suplicante, su mujer e hijos quedarán perdidos y destruidos sin tener de que alimentarse fuera de que es en beneficio de la causa pública el que también las imprima por ser como es su imprenta mucho más numerosa" (Archivo General de Navarra. Tribunales Reales, Procesos, núm. 76784, fol. 1v).

Pero ante esta demanda Martín de Ilarregui, abogado de Martín Gregorio, argumentó en su defensa que "el aguelo y padre de mi parte fueron impresores de este reino por espacio de más de cuarenta años con títulos de la Diputación y Regimiento de esta ciudad sin que otro alguno los tuviese hasta que murieron y en remuneración de dichos servicios la dicha Diputación y Regimiento le dio también a mi parte título en la misma forma diciéndole juramento como se acostumbra" (Archivo General de Navarra. Tribunales Reales, Procesos, núm. 76784, fol. 7r). 
En defensa de los demandantes salió José Cuadrado, su procurador, para alegar que Martínez "ha sido y es impresor de este reino y ciudad y como tal imprimió el Cuaderno de las Leyes de las últimas cortes y las investigaciones históricas de este reino y otras muchas impresiones". A esto añadía lo más importante, ya que reconocía que la imprenta era de Isabel, ya que:

Martín Gregorio de Zabala trabajaba como oficial por el salario de cuatro reales que le daba en cada día Isabel de Labayen, su madre, y mujer de mi parte por cuanto no tenía ni tiene imprenta propia suyas y en la que trabajaba al tiempo era y es de la dicha su madre, con que la gracia y facultad que se le dio para que pudiese imprimir no parece que se puede entender con la parte contraria pues aquella no se le hizo en el auto acordado de vuestro consejo en contemplación suya ni determinadamente a él, sino de la dicha su madre. (Archivo General de Navarra. Tribunales Reales, Procesos, núm. 76784, fol. 8r)

Comprobamos, por tanto, que de manera explícita se estaba indicando que el taller de imprenta de Martín de Labayen era de su hija Isabel, quien había sido su única heredera, por lo que ni su segundo marido ni su hijo eran los dueños.

Queda patente tras los testimonios rescatados que Isabel de Labayen quizás no ejerció el grado de control o tuvo el protagonismo que se atisba en otras mujeres, caso de Juana Millán en la Zaragoza del siglo XVI (Pedraza Gracia, 2009: 59-70), pero se evidencian situaciones análogas en el devenir de ambas impresoras. En definitiva, lo que se deja entrever de la documentación de archivo consultada es que Isabel ejerció no ya como heredera del taller de su padre, sino que desarrolló labores administrativas como regente de su negocio y también cometidos técnicos en su faceta de impresora.

\section{UNA PAMPLONESA EJERCIENDO COMO IMPRESORA Y EDITORA}

Como se ha indicado al principio de este trabajo, la presencia de la mujer en la imprenta navarra del siglo XVII no fue muy relevante o, al menos, han dejado pocos testimonios documentales. Es por esto que la figura de Isabel de Labayen cobra si cabe mayor protagonismo, ya que, como acabamos de ver, queda patente cómo defendió su legado y su sustento de vida frente a quienes atentaban contra él, bien fuese su segundo marido, su hijo o cualquier otro, caso de los libreros pamploneses. No obstante, junto a los recursos archivísticos -procesos judiciales y escrituras notariales- que nos permiten conocer dicha situación, no podemos obviar las evidencias que dejan entrever algunos impresos conservados. 
Estos últimos son los que nos permiten comprobar si manifestó públicamente su ejercicio como impresora y, además, como dueña del taller de imprenta radicado en Pamplona. Lo cierto es que no son muchos los impresos que se han conservado (Itúrbide Díaz, 2015: 184), pero sí que nos sirven todos ellos para evidenciar que entre 1669 y 1670 se produjo una fractura en las relaciones de Isabel con su hijo, lo que provocó que ante el abandono de Gaspar Martínez optase por visibilizar su nombre como impresora y regente del taller heredado de su padre, en clara defensa de sus derechos y prerrogativas como dueña de dicha imprenta.

En primer lugar, tal y como se aprecia, hay un impreso que data de 1669 (Figura 1) que se trata del Pronostico y Lunario del Año del Señor de 1670, en cuyo pie de imprenta podemos leer el siguiente texto: "Con licencia, en Pamplona, por Ysabel de Labayen. Año 1669. Vendese en la misma Imprenta”. Se trataría así de una edición para reivindicar la posesión del taller como heredera de Martín de Labayen frente a los intentos de su hijo mayor por hacerse con el negocio familiar. Sabemos que hasta entonces Martín Gregorio había estado trabajando en el taller de su madre, por lo que ya apreciamos un salto cualitativo en su relación personal.

En este impreso, por vez primera, Isabel decide poner su nombre como impresora, actuando al mismo tiempo como editora. El hecho de que indique dónde se vende dejaba también a las claras que el negocio lo regentaba ella. Este ejemplar, por tanto, es de suma importancia porque marca un cambio de tendencia; además, debemos tener en cuenta que se trata de un impreso que era inédito hasta el momento y que lo localizamos en el Archivo General de Navarra en un proceso judicial que dirimieron Martín Gregorio de Zabala y su madre. ${ }^{2}$

No obstante, aquel cambio se consolidó en 1670, ya que en dicho año pasó a utilizar ya en el pie de imprenta el siguiente texto: "En la Imprenta de Isabel de Labayen. Año 1670". Que sepamos lo empleó en cuatro impresos, ya que Pérez Goyena (1949: 452 y 454) menciona dos que no hemos podido encontrar con la misma fórmula. ${ }^{3}$ Pese a esto, lo que pone de manifiesto esa manera de referirse al taller como suyo es la disputa abierta con su hijo desde finales de 1669 y que se recrudeció a lo largo de 1670. Aquel enfrentamiento habría provocado ese cambio y el hecho de que ella misma dijese que dichos impresos (Figuras 2 y 3) se habían publicado en su imprenta, a diferencia de lo que sucedía un año antes, cuando simplemente indicaba que ejercía como impresora.

2 Es un impreso que Pérez Goyena no recogió en su Ensayo de Bibliografía navarra (1949). El pleito en cuestión se encuentra en el Archivo General de Navarra. Tribunales Reales, Procesos, núm. 76675.

3 Se trata de dos alegaciones en derecho con los números de entrada 658 y 661. 


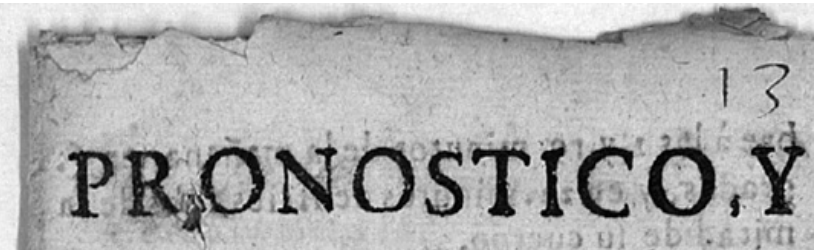

Lunario del Ano del Senor de $1690^{\circ} n$ de cada dia de porfi, y de quartos de Luta, con los Eclipfes de Sol, y Luna, juizio del año, y colecha de fratos, y atantinimientos, al meridiano de Navarra de Valladolid,Caf́n of

- tilla la Vieja,y Nueva, Aragon, y otras Y. 2000 partes, con/poca diferencia,

CON LAS FIRSTAS DE GVARDAR; legun el Miotu propio de Vrbano OAtauo.

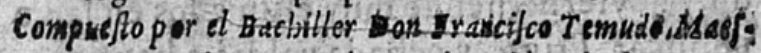
- Tro de Natematices en lo roble,y leal

\section{caste ciudad de Velladolid.}

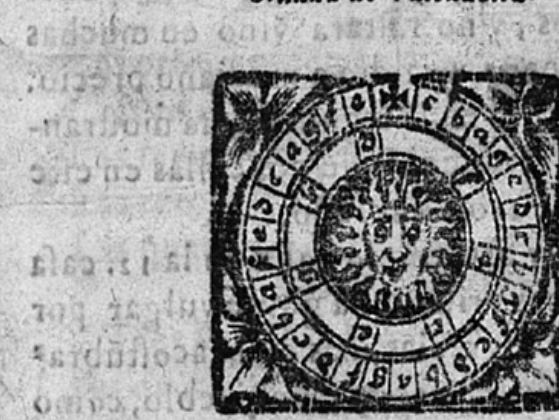

Con licencia, en Pampiona, por Yrabel de Labayed

20IJ) 23r Ljẩ Año 1669 .

- La D Vendeferala mifmaimpreria,

Figura 1. Portada: Pronostico y Lunario del Año del Señor de 1670... (Archivo General de Navarra. Tribunales Reales, Procesos, núm. 76675 [foto de autor]) 


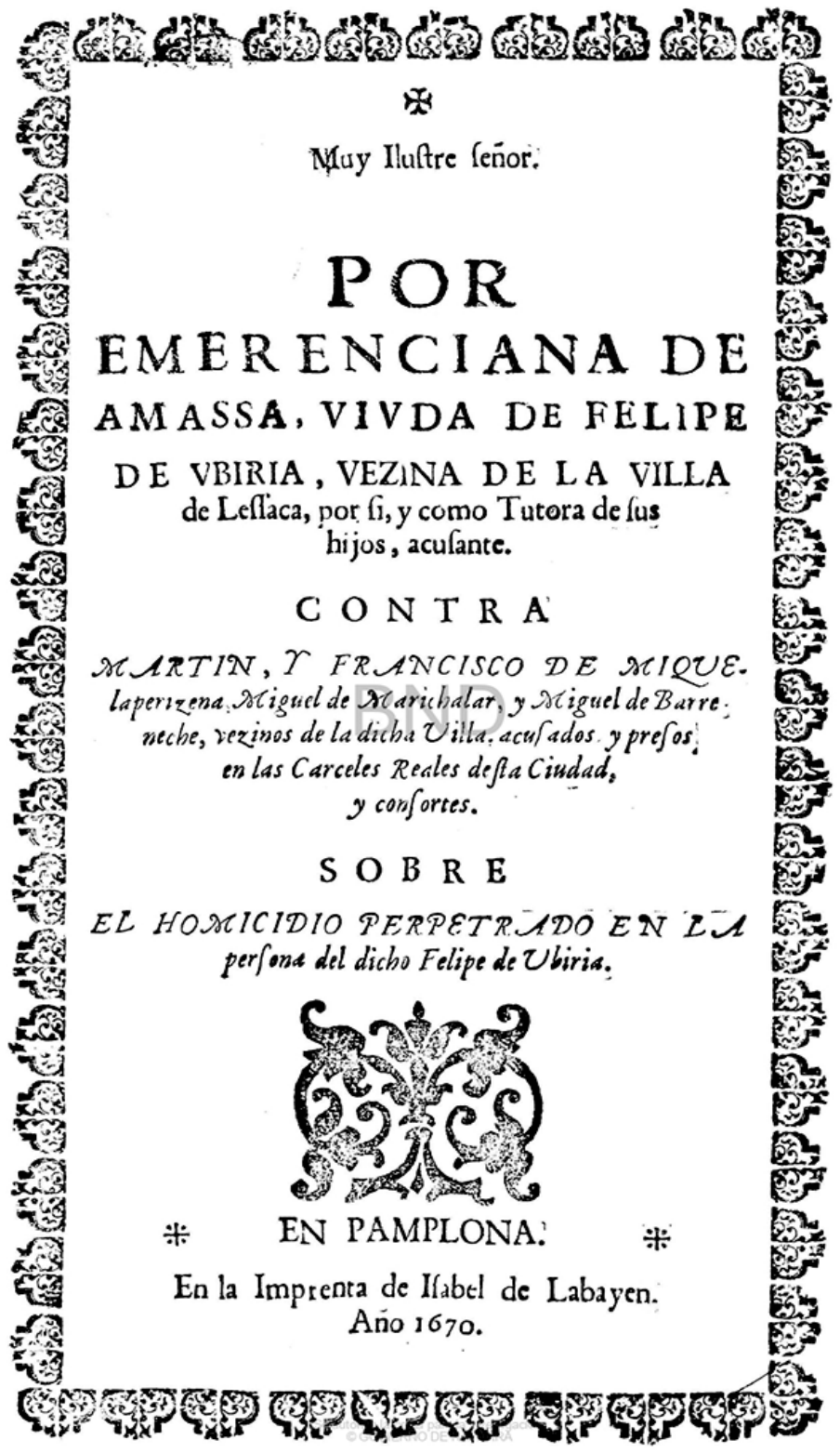

Figura 2. Portada: Por Emerenciana de Amassa... (Biblioteca Capitular de Pamplona: A-Caja 4002/9-1 [foto de autor]) 


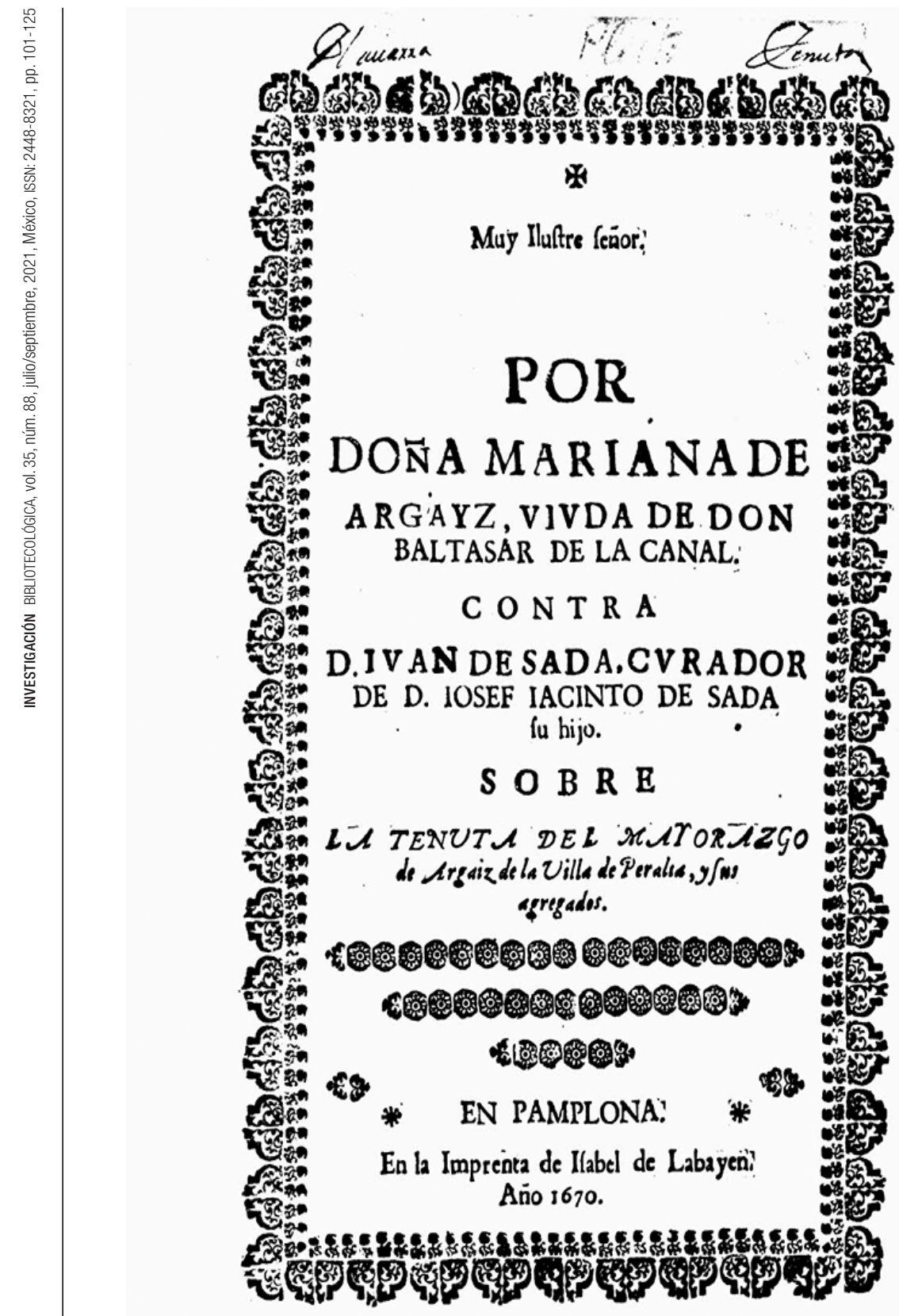

Figura 3. Portada: Por Doña Mariana de Argayz... (Biblioteca General de Navarra: Ca 60/3188 [foto de autor]) 
De todas formas, pese a estas dos alegaciones en derecho editadas en 1670 que se han localizado, no se han encontrado testimonios más allá de ese año porque para 1671 regresó de Zaragoza su segundo marido, por lo que a partir de entonces volvería a aparecer Gaspar Martínez en los pies de imprenta y colofones. Resumiendo, se advierten algunos impresos que llevan en el pie de imprenta su nombre o alguna referencia a ella. En dichas evidencias bibliográficas nos podemos encontrar con dos maneras diferentes de reflejar su papel al frente del taller de imprenta por aquellos años, al mostrarse como impresora-editora y, a su vez, también como titular-regente del negocio:

1. "Por Ysabel de Labayen" (1669).

2. "En la Imprenta de Isabel de Labayen” (1670).

Sea más o menos explícita la mención que se recoge en algunos de estos impresos, lo que se atisba gracias a ellos y que podemos constatar en última instancia es que Isabel de Labayen ejerció un papel protagonista en el proceso de edición y comercialización como dueña de un taller de imprenta. Esto se constata del Pronostico y Lunario del Año del Señor de 1670 que publicó en 1669, por el cual su hijo le demandó ante las deficiencias tipográficas que reunía (Figuras 4 y 5).

Sabemos que este tipo de producto editorial, como argumentó Moll Roqueta (1996: 260), era una publicación altamente demandada que se había afianzado entre las costumbres lectoras de la sociedad áurea, de ahí que diese interesantes réditos su edición y comercialización, más en un reino tan pequeño como Navarra. Todo esto, junto al hecho de que apareciese dicho pronóstico con el nombre de Isabel en el pie de imprenta habría exasperado los ánimos de Martín Gregorio de Zabala.

Así comprendemos que alegase en su defensa contra su madre que "lo que se imprime por cuenta de la dicha Isabel de Labayen tiene muchos defectos, como consta de el pronóstico que presento en que no corre la colocación de las llanas pues pone primero el mes de marzo que los de enero y febrero" (Archivo General de Navarra. Tribunales Reales, Procesos, núm. 76675, fol. 17r). Además, en portada (Figura 4) se aprecian erratas que aparecen señaladas al margen, caso de "Ano" que debía ser sustituido por "Año" o "de Valladolid" que tendría que enmendarse por "\& Valladolid". 
-כ!Nל1

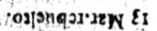

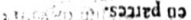
sodanj o्र

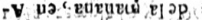

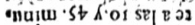

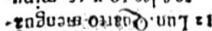
i.i.i. comjra opwog 14

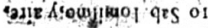
spвo otajtw o[ $21 \wedge 6$ copridwas squ.anis

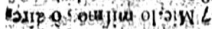

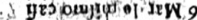
- che fsusid us

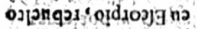

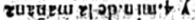
z sef e zuมा

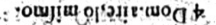

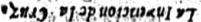
osjonq5j'ocuj!u o| qes $\varepsilon$

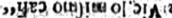

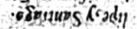

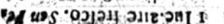

andeวas ruzuew rlo

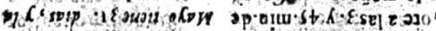

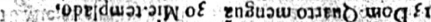

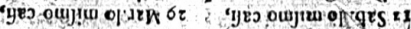

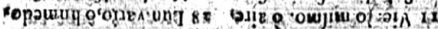

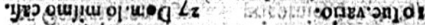
19)

\section{Sater $=2$}

Dexiewhe, riene') diass,

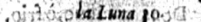

i Kun templado, bielo.

2 Mar lo mifmo

3 Miej lomilne cafi.

4 lue Quarto menguag

2 las 7 >51. min do la

- Imañansico $V$ ingo,frie sebaelto, hielo.

STistomímo enfi.

6 Sab hiclo frio,

7dBomivarió o aire.

8 Lph to milno cafiz Isa

Censecion de 7 - Seriora.

gMar humedo, varia.s

tapdie do mitaro, fúc.

1t due tebutte, fria:

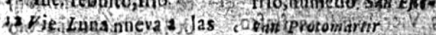

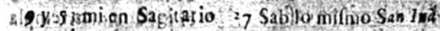

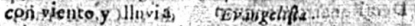

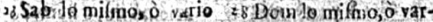

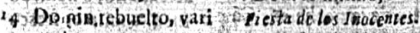

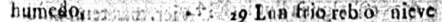

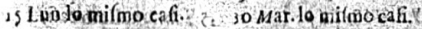

16. Marc mas seapplado. ${ }_{3}$ Mie defódefe el 250

z Miér frios hielo. is is contunscho frio, y hic-

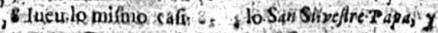

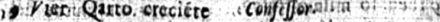

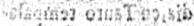
DIOS SOBRE TODO. vingor

-oprdaus seu'כrw 6

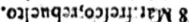

- osjanqaroueann $l$

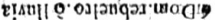

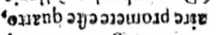

K'rเan|| rungi 'esqiT

a'zip jop.jnniw-st $A$ :

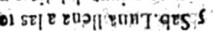

owjux ol'sne'כis $t$ yejoldodds: on

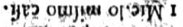

opE)dw

- ov'vint

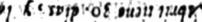

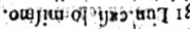
'yes owytu of ued of otwiru o/ 9 क्s $65^{\circ}$

- opjakropejduas

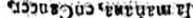

ap unum.LS \& g sí

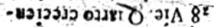

ớtajití ol วnI $L \tau$

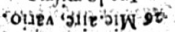

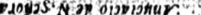

on 'olnes'vilerobs us

oT IJ

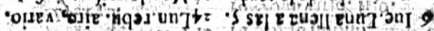

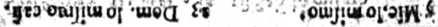

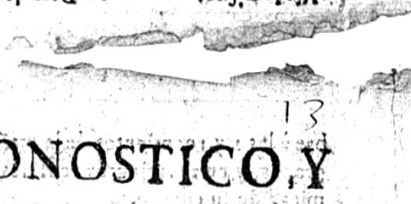

Lunario del Ano del Señor de $16 \%$ a

de cada dia de porfi, y de quartos de Luón. con los eclipfes de Sol, y Luna, juiziodel ańo, y colecha, de fratos s bantinimiencos, - Imeridiano de Navara de Valladolid Cal. tilla la Vicja, y Nucra, Aragon,y otras partes, con poca difercocia.

CON LAS FIESTASDE GVARDAR fegun el notu propio de vrbano Oetaua.

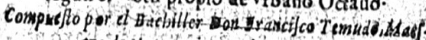
tro de Mateinatic es en 72 noble, y lial cividad de Valladolid.

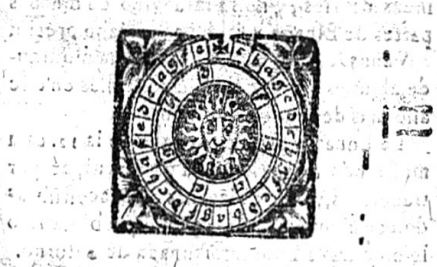

Con lisencia, en Pa mplona, por Yrabel de Iabayed Año 1669 . Vendeje co lo mifm a Injucura,

Figura 4. 1er Pliego: Pronostico y Lunario del Año del Señor de 1670... (Archivo General de Navarra. Tribunales Reales, Procesos, núm. 76675 [foto de autor]) 


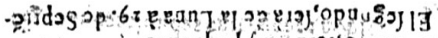

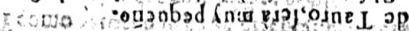

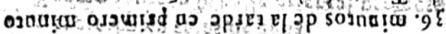

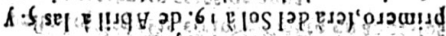

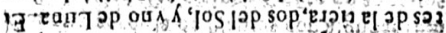

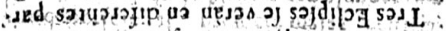
ipun 7 cos top soddury

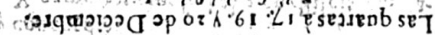

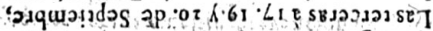
y. ofsew op orom

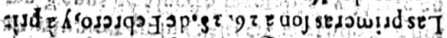
Ectorodus oos ond.

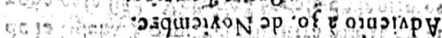
ojanjop's e jujajondsoj odeW op 5 z rojues nuidj op enojed

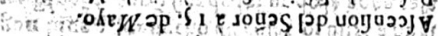
(z) ofew गp zi esuopsay

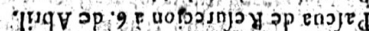
-ososqog sp 61 e es!ajo op r! व

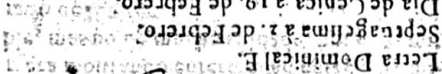

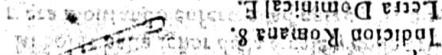

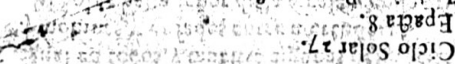

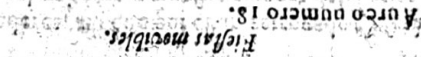

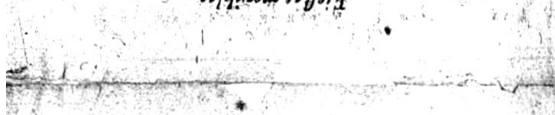

2Dom.tominocifo ta o nieve en tierasfrias parificactóde N. Seriera a 6 Dom fo míno cafi, - Eun tébuélto, aire, frio, 17 Lun. aite, rebirelto,

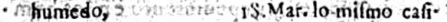
4 Mart Luna lleua a lás ig Mie. Luranueva a las - sooy róminutos dela 13 y 24 minidela nopoches enleon, frio, che en Pilcis,con algo, conlluyia, yaire, y nie vario, y hmedo en

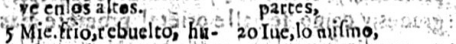
medon ro

6 Iúciate furiornieve en si Sabyario. vigilia,

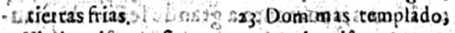

- Vieflomifmo cafi, 34 Lún, lo nifmo. San Mis

8 Sab,vario, tias defle oh?

Dom. aire,vario 25 Maraire vario.

10 Lun.lo milmo cafi, 36 Mie. Quarto crecien,

XIMraite, vatio, te alas 4 y 24 minat.

fr Me. Oaktto mégua de latarde, en Gemi-

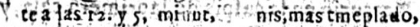

- Celela táchielama nécié 27 Iue templado.

- Lo para di dja hueces: as vie.lo mismorafi,

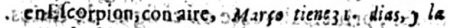

- yituviáfrio, turbacion Linna 30 .

de aire y nieve en los i Sab cemplado, aire, altớs, 2 Dom lonilino,

is toe tứrbio, frio bum, 3 Lun remplado,

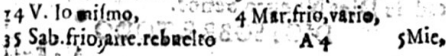

$35 \mathrm{Sab} . \mathrm{frio}$
9

cosfdresparsurs. yes oum!ni or taoc 0 vilis A oujlu of $9 \mathrm{~s}$,

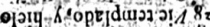
oujtu olon $L_{2}$

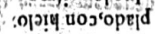

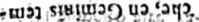
-ou riop sojnutu. 65

A 6 set $x$ guall zuntso

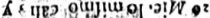

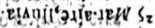
ives owj!

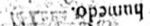

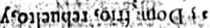

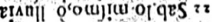

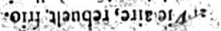
z opel

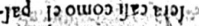
couprnbe ua r gueury

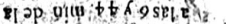

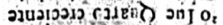
ords ذार गार 6

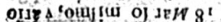
yep owjew of ung 5 , oisérianthogos

- on

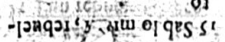

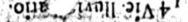

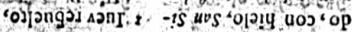
SPPMi, s solu

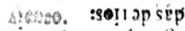

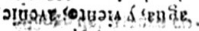
uoj' ordjoj3 u2 s.ap.

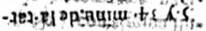
spict ratasentantit 'כunY DHEcoldeA IETE cothsy otaj!w ofra7 ธIA ijex oujsut of 'qes 8 orujop

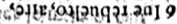
sopysoperdwaj

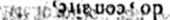

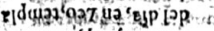
sounuely st d a se $B$ ajuengusas oduenbs

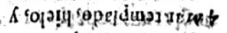
4590 (y)

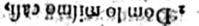
ssorues sopol ap vy

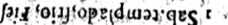
\&

G. vint of $\mathrm{C}$

'svip of ausn asquisias

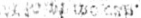

Sid othipu oj'dara is copediuss ancos

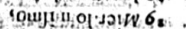

\section{Mié.aire.}

Is Iue, lo mifno, ó ratio 16 Vie re.

is Sab lo milmo cafi - 81 Dom lo mírino cafi

Io Lun: Luoa nueva a la

if $16, \mathrm{~min}$.

tatha, en Tauro, co

algun viento, y humedo en partes.

20 Mar.rebuelco, aire

21 Mier. Ig mifnos of

medo.

23 Ióe, yario, aire

23 Vier.varia:

24 Sab.lo milmo cafi, 10 Mar. Quatto mengua-

35 Domrtemplado,

26 Lurr. Quarto crecie日:-

te $3 / 253$ y 50 min.de

la tardejen Yirgo,con in Mie lo mílmo cafi,

algunallavia, ò aire, 12 Iue.lo mfme.

xario, rebaelto en par-

tes, à truenos,

27 Mar tebuolto

43. Vieicalor,aire.

14 Sab lo mifmo rebueito

15 Dom. fo miforo, y ca -

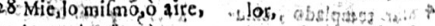

29. Luev rebuefte, ò true- 16 Lun viento yrebuelta

nos. 7 or 77 Mar. Luna nueva a las

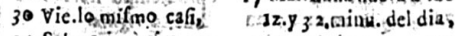
31. Sab,yario, o afre, 
Pero más allá de las erratas o las posibles mejoras que advirtió Martín Gregorio en el impreso publicado por su madre, lo reseñable es que ella se ratificó un año después en los dos impresos que hemos recogido, aunque probablemente haya alguno más de 1670 que no hemos conseguido encontrar. En ambos, como se aprecia en los pies de imprenta, ya señalaba que aquellas alegaciones en derecho se habían editado en su taller, remarcando así la propiedad del mismo como heredera directa de su padre (Martín de Labayen).

Independientemente de esto, lo que se comprueba a través de los testimonios bibliográficos rescatados es que Isabel, más allá de ejercer como regente del negocio familiar, también actuó -al igual que otras mujeres del siglo XVII- como editora e impresora en momentos puntuales. Esta navarra, como es lógico, cabe pensar que habría aprendido en el seno de su familia el arte y oficio de la imprenta, algo que era habitual dado que los negocios editoriales eran transmitidos a las hijas con bastante asiduidad.

\section{Conclusiones}

A finales de la década de los años 80 del siglo pasado Margarita Ortega López señalaba que la historia de las mujeres era una corriente en ciernes, ya que "tradicionalmente la historiografía había ignorado sistemáticamente a las mujeres como sujeto histórico" (1987-1988: 159). No podía ser más acertado su apunte, el cual se agranda en lo que a la mujer en el negocio editorial se refiere, ya que el olvido manifiesto en el que ha estado sumida ha procedido tanto desde el campo de la Historia del Libro como de la Bibliografía.

No hay duda de que la investigación pormenorizada y concreta de cada una de estas mujeres que se emplearon en el mercado del libro nos ayudará a obtener una imagen de conjunto que nos permita esbozar cuál fue la actividad y el grado de implicación real de muchas mujeres en el negocio editorial. No obstante, para redescubrir el protagonismo que tuvieron algunas en la imprenta áurea resulta imprescindible cruzar diversos testimonios documentales. Y más cuando los nombres de muchas de ellas, si nos limitamos a las evidencias bibliográficas, resultan inescrutables porque casi ni aparecen en los pies de imprenta y colofones frente al dominio ejercido por los nombres masculinos. En consecuencia, resulta conveniente cotejar los impresos en busca de referencias en los pies de imprenta y colofones, aunque los datos que extraigamos tendrán que ser analizados junto a las informaciones recuperadas en los documentos de archivo, procedentes principalmente de los procesos judiciales y las escrituras notariales.

Sólo así seremos capaces de obtener una imagen lo más aproximada posible a su verdadero papel en el entramado editorial. Al menos esto es lo que se 
trasluce del presente trabajo, en el que se ha puesto de manifiesto la defensa a ultranza que hizo Isabel de Labayen de su taller de imprenta frente a las injerencias de su hijo mayor y de su segundo esposo, además de las provocadas por ciertos libreros pamploneses. Pero más allá de ese papel de regente se ha constatado que también ejerció como impresora y editora entre 1669 y 1670 al disponer su propio nombre en varios pies de imprenta. Todo esto, en suma, nos arroja nuevos testimonios que nos permiten redescubrir la figura de una mujer que aparecía cubierta bajo el tupido manto de varios hombres, caso de Gaspar Martínez y Martín Gregorio de Zabala.

Es evidente que ambos, fruto de la estructura familiar de este tipo de negocios, tienen una mayor presencia en los impresos que se publicaron en su taller, pero lo importante es que ella como heredera era la dueña real del negocio. Tal vez calibrar su grado de colaboración en las tareas editoriales cuando estaban al frente su segundo esposo o su hijo mayor resulte sumamente complejo e inabordable, pero lo que resulta evidente es que durante esa regencia que comenzó a partir de 1662 y se alargó hasta 1671 su participación se tornó mucho más activa tomando las riendas de la imprenta.

En definitiva, en el presente artículo tanto los datos de archivo como las evidencias bibliográficas rescatadas nos informan sobre la existencia de una mujer llamada Isabel de Labayen que desempeñó un papel de suma relevancia en la imprenta navarra de la segunda mitad del siglo XVII. Si bien solamente podemos reconstruir de manera parcial el grado de intervención que realmente habría llegado a ostentar nuestra protagonista, cabe afirmar sin temor a equivocarnos que estamos ante un caso único en la historia del libro en la Pamplona áurea, puesto que ejerció como regente, impresora y editora. Nos encontramos, por tanto, con una mujer que dentro de un negocio eminentemente masculino fue mucho más que una hija, esposa o madre.

Agradecimientos

Esta contribución se ha realizado en el marco del proyecto de investigación Biblioteca Digital Siglo de Oro 6 (BIDISO 6), con código PID2019105673GB-i00, financiado por el Ministerio de Ciencia e Innovación de España, por el pro-grama estatal de Generación del Conocimiento (01/06/2020 al 31/05/2023). El proyecto BIDISO se integra en el grupo de investigación HISPANIA (G000208) de la Universidade da Coruña, que ha conseguido una ayuda de consolidación de la Xunta de Galicia (ref. ED431B 2019/28). 


\section{REFERENCIAS}

Corbeto López, Albert. 2009. "Las musas ignoradas. Estudio historiográfico del papel de la mujer en el ámbito de la imprenta", en Muses de la imprenta. La dona i les arts del llibre. Segles XVI-XIX, editado por Marina Garone Gravier y Albert Corbeto López, 2-42. Barcelona: Museu Diocesà de Barcelona/Associació de Bibliòfils de Barcelona.

Cortés Corral, Mónica y María Victoria Méndez Viar. 2001. “Impresoras madrileñas en el Siglo de Oro: Juana Martínez de Angulo”. Anexos de Signo 4: 185-211.

Delgado Casado, Juan. 1996. Diccionario de impresores españoles (siglos XV-XVII). Madrid: Arco Libros. 2 vols.

Establés Susán, Sandra. 2018. Diccionario de mujeres impresoras y libreras de España e Iberoamérica entre los siglos XV y XVIII. Zaragoza: Prensas Universitarias de Zaragoza.

Fernández Vega, María del Mar. 2004. "Jerónima de Gales. Una impresora valenciana del siglo XVI", en La memoria de los libros. Estudios sobre la historia del escrito y la lectura en Europa y América, coordinado por Pedro Manuel Cátedra, María Isabel de Páiz y María Luisa López-Vidriero, 405-434. Salamanca: Instituto de Historia del Libro y de la Lectura.

Garone, Marina. 2008. "Impresoras hispanoamericanas: un estado de la cuestión". Butlletí de la Reial Acadèmia de Bones Lletres de Barcelona 51: 451-471.

Garone, Marina y Albert Corbeto. 2011. "Huellas invisibles sobre el papel: las impresoras antiguas en España y México (siglos XVI al XIX)”. Locus: Revista de Historia 17 (2): 103-123.

Gregori Roig, Rosa Maria. 2012. La impressora Jerònima Galés i els Mey (València, segle XVI). València: Biblioteca Valenciana Nicolau Primitiu-Generalitat Valenciana.

Infantes de Miguel, Víctor. 2012. "La muestra de impresión: un testimonio inédito de la estrategia editorial del Siglo de Oro", en Edición y literatura en España (siglos XVI y XVII), coordinado por Anne Cayuela y Roger Chartier, 137-168. Zaragoza: Prensas Universitarias de Zaragoza.

Itúrbide Díaz, Javier. 2015. Los libros de un reino: historia de la edición en Navarra (1490-1841). Pamplona: Gobierno de Navarra.

Moll Roqueta, Jaime. 1996. "El privilegio del calendario anual en el siglo XVII", en Las Relaciones de sucesos en España (1500-1750), coordinado por Henry Ettinghausen, Víctor Infantes, Augustín Redondo y María Cruz García de Enterría, 253-260. Alcalá de Henares: Universidad de Alcalá.

Ortega López, Margarita. 1987-1988. "Una reflexión sobre la historia de las mujeres en la Edad Moderna”. Norba. Revista de Historia 8-9: 159-168.

Pedraza Gracia, Manuel José. 2009. “Juana Millán, señora de la imprenta: Aportación al conocimiento de una imprenta dirigida por una mujer en la primera mitad del siglo XVI”. Bulletin Hispanique 111 (1): 51-73.

Pérez Goyena, Antonio. 1949. Ensayo de Bibliografía navarra. Desde la creación de la imprenta en Pamplona hasta el año 1910. Pamplona: Diputación Foral de Navarra.

Ruiz Astiz, Javier. 2015. "Litigantes ante los Tribunales Reales de Navarra: impresores y libreros durante los siglos XVI y XVII”. Titivillus. Revista Internacional sobre Libro Antiguo 1: 325-339. 
Ruiz Astiz, Javier. 2020. "El papel del autor en la imprenta pamplonesa del siglo XVII. Intrahistoria de las obras de José de Moret”. Anales de Documentación 23 (2): 47-63.

Rumeu de Armas, Antonio. 1971. "Isabel de Basilea, ¿mujer impresora?”. Bulletin Hispanique 73 (3-4): 231-247.

Sánchez Cobos, María Dolores. 2004. "Mariana de Montoya, una mujer impresora en la Baeza de comienzos del XVII", en La memoria de los libros. Estudios sobre la bistoria del escrito y la lectura en Europa y América, coordinado por Pedro Manuel Cátedra, María Isabel de Páiz y María Luisa López-Vidriero, 365-379. Salamanca: Instituto de Historia del Libro y de la Lectura.

Ulla Lorenzo, Alejandra. 2018. “¿Viudas de mercaderes o verdaderas mercaderas? Mujer y comercio de libros en los siglos XVI y XVII”. Hipogrifo 1: 321-340.

Vázquez Madruga, María Jesús. 2010. "Juana Martínez de Angulo: una impresora de Alcalá de Henares a finales del s. XVI”. Cuadernos para investigación de la literatura hispánica 35: 83-102.

Para citar este texto:

Ruiz Astiz, Javier. 2021. "Isabel de Labayen: impresora y editora en la Pamplona del siglo XVII". Investigación Bibliotecológica: archivonomía, bibliotecología e información 35 (88): 101-125.

http://dx.doi.org/10.22201/iibi.24488321xe.2021.88.58423 